\title{
ES Cell-derived Erythroid Cell Lines Able to Produce Mature Red Blood Cells
}

\author{
Yukio Nakamura \\ Cell Engineering Division, RIKEN BioResource Center \\ Japan
}

\section{Introduction}

Transfusion therapies involving red blood cells (RBCs), platelets, and neutrophils depend on the donation of these cells from healthy volunteers. However, unpredictable adverse results can ensue from transfusion therapies because of the donation of cells from a very large number of anonymous volunteers. For example, transfusion of blood products that include hazardous viruses or prions is difficult to prevent completely because, occasionally, tests to detect them yield pseudo-negative results. This comment is, of course, not intended as a criticism of the current system that is dependent on volunteers who act as blood donors from their own good will. However, there is little doubt that RBCs, platelets, and neutrophils produced in vitro might be a preferable means of producing such cells, thereby reducing, or even eliminating, the need for a large pool of anonymous donors. To date, however, the use of hematopoietic cells produced in vitro has not proved practical for routine therapeutic applications.

$\mathrm{RBC}$ transfusion was the first transplantation procedure to be established and is now routine and indispensable for many clinical purposes. However, in many countries the supply of transfusable materials is not always sufficient. In Japan, for example, the supply of RBCs with an $\mathrm{AB} / \mathrm{RhD}(-)$ phenotype is always lacking because individuals with this $\mathrm{RBC}$ phenotype are rare. This problem of inequalities in the supply and demand for RBCs has stimulated interest in the development of in vitro procedures for the generation of transfusable and functional RBCs from hematopoietic stem cells or progenitor cells present in bone marrow or umbilical cord blood (Figure 1) (Neildez-Nguyen et al., 2002; Giarratana et al., 2005; Miharada et al., 2006; Douay and Andreu, 2007).

In addition, it is important to realize that clinical risk factors associated with RBC transfusions have not been entirely excluded. One notable and very severe complication of the procedure can be transfusion-related acute lung injury (TRALI), which has only recently been recognized and has not yet been eliminated (Silliman et al., 2009; Looney et al., 2010). One of the possible causes of TRALI may be a factor in the transfused materials, such as antibodies in the transfused materials against antigens on the leukocytes. This type of adverse outcome also results from the dependence of blood transfusion on the supply of blood from a large number of anonymous individuals. Problems may arise if donated blood is utilized without sufficient preliminary trials being carried out on each sample. The use of RBCs derived from selected human resources may help to alleviate these problems, since they can be intensively tested for pathogens before clinical use. Trial transfusions of a minimal amount of material into each 
recipient could also be performed to determine if there are unexpected complications. Therefore, the establishment of resources for in vitro production of RBCs (Figure 1) will provide a means to alleviate many problems associated with RBC transfusion.

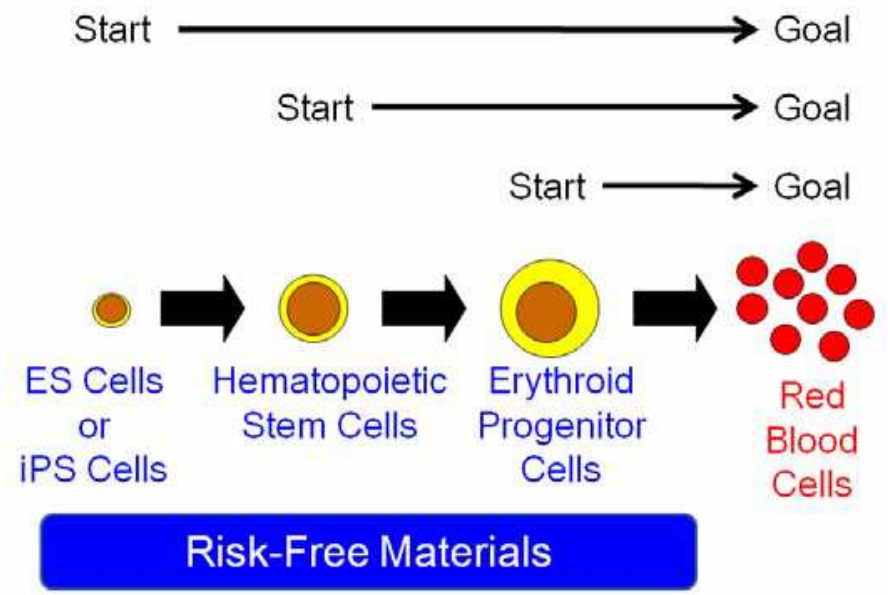

Fig. 1. A summary of some of the ways in which RBCs could be produced in vitro.

\section{RBC production from hematopoietic stem cells}

The hematopoietic stem cells present in bone marrow and umbilical cord blood are promising materials for in vitro production of RBCs and this has stimulated interest in the development of in vitro procedures for the generation of functional RBCs from these tissues (Neildez-Nguyen et al., 2002; Giarratana et al., 2005; Miharada et al., 2006). Umbilical cord blood cells are of particular interest as they are readily available but are usually discarded. Provided the mother of a neonate consents to use of the umbilical cord blood, this material can provide a useful resource without any further complicating critical or ethical concerns. It was reported that human erythroid cells (nucleated cells) produced on a large scale ex vivo could differentiate in vivo into enucleated RBCs (Neildez-Nguyen et al., 2002). This study demonstrated that erythroid progenitor cells produced in vitro from hematopoietic stem and progenitor cells could have a clinical application as an alternative method for transfusing terminally differentiated RBCs. More recently, the same group described an ex vivo methodology for producing fully mature human RBCs from hematopoietic stem cells (Giarratana et al., 2005). The enucleated RBCs produced by this approach are potentially even more valuable as they should be functional immediately after transfusion without requiring the long latency period for enucleation normally necessary for erythroid cells.

The mechanism of erythroblast enucleation, a critical step in RBC production, has not yet been fully elucidated (Lee et al., 2004; Kingsley et al., 2004). The role of interactions between erythroblasts and other cells, such as macrophages, in this process is a controversial topic (Ohneda and Bautch, 1997; Yanai et al., 1997; Hanspal et al., 1998; Iavarone et al., 2004; Spike et al., 2004). Macrophages in retinoblastoma gene ( $\mathrm{Rb}$ )-deficient embryos are unable to physically interact with erythroblasts and RBC production is impaired in these embryos (Iavarone et al., 2004). In addition, in vitro production of enucleated RBCs from immature 
hematopoietic stem/progenitor cells proceeds efficiently in the presence (Giarratana et al., 2005) but not in the absence (Neildez-Nguyen et al., 2002) of feeder cells.

Of note, however, enucleation can apparently be initiated in vitro in erythroblasts that have been induced to differentiate in vivo to a developmental stage that is competent for nuclear self-extrusion (Spike et al., 2004; Yoshida et al., 2005). Moreover, we have developed a method to produce enucleated RBCs efficiently in vitro without use of feeder cells (Figure 2) (Miharada et al., 2006). The culture system has allowed erythroid cells to differentiate to a developmental stage competent for nuclear self-extrusion (Miharada et al., 2006). Taken together, although it has generally been thought that efficient enucleation of erythroblasts is largely dependent on signals mediated by cells in their local environment (Ohneda and Bautch, 1997; Yanai et al., 1997; Hanspal et al., 1998; Iavarone et al., 2004), the interaction of erythroblasts with other cells is not necessary for efficient erythroblast enucleation (Miharada et al., 2006). Signals mediated by humoral factors appear to be sufficient for the efficient autonomous completion of erythroblast enucleation.

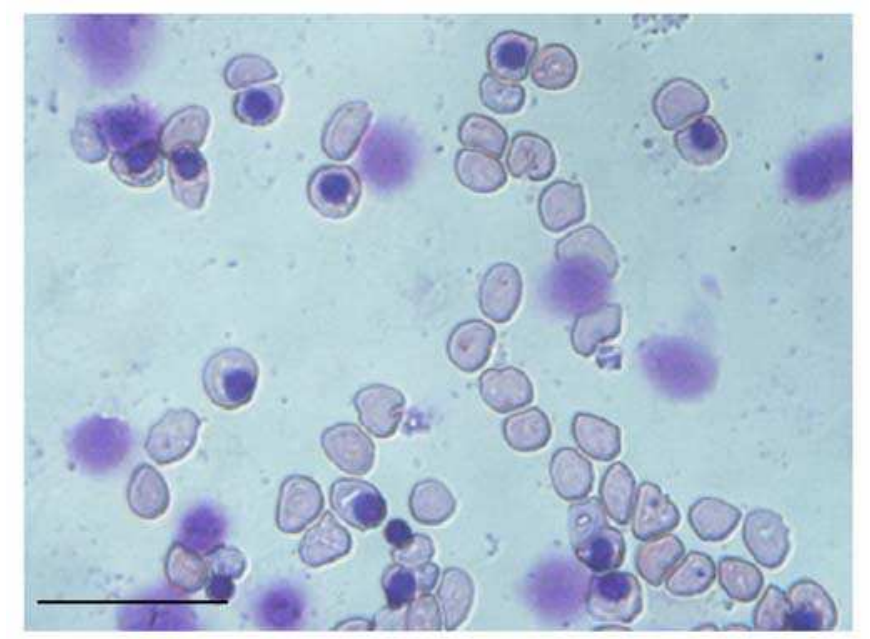

Fig. 2. Enucleated RBCs produced in vitro from hematopoietic stem cells. Scale bar indicates $50 \mu \mathrm{m}$.

Since culture without the use of feeder cells is technically easier and less expensive, the method we established (Miharada et al., 2006) has the potential to be a cost-effective means of producing transfusable $\mathrm{RBCs}$ on a large scale from immature hematopoietic stem/progenitor cells. Currently, however, cost factors means that it is not yet realistic to produce RBCs on a large scale, approximately $200 \mathrm{ml}$ or more, using our in vitro culture system. In particular, patents on the growth factors used in the culture system are a major obstacle, because these growth factors are very expensive, at least at the moment. After the relevant patents expire, our in vitro culture system will become a more realistic scenario.

\section{RBC production from ES cells}

ES cells possess the potential to produce various differentiated cells able to function in vivo and thus represent another promising resource for RBC production. Furthermore, since ES 
cell lines are immortalized, they can be used repeatedly and have potential to produce abundant differentiated cells in the quantities required for clinical use. However, it will be important to carry out routing screening of the ES cell lines for de novo chromosomal aberrations and/or genetic mutations that may arise in vitro, before these long term cell cultures are applied in the clinic. Unsurprisingly, there is now a widespread and enthusiastic debate on standardization of the characteristics of ES cells for regenerative medicine protocols that exploit these cell lines. In my opinion, since chromosomal aberrations and genetic mutations are inevitable in long term cell cultures, only ES cell lines that have been cultured for a limited period, e.g., less than 30 passages, should be selected for clinical use.

Hematopoietic cells, including those in the erythroid lineage, have been generated from mouse ES cells (Keller et al., 1993: Nakano et al., 1994; Nakano et al., 1996; Carotta et al., 2004), non-human primate ES cells (Li et al., 2001; Umeda et al., 2004; Kurita et al., 2006), and human ES cells (Kaufman et al., 2001; Chadwick et al., 2003; Cerdan et al., 2004; Vodyanik et al., 2005; Wang et al., 2005; Olivier et al., 2006). We have also established a longterm in vitro method for culturing hematopoietic cells derived from ES cells of the nonhuman primate, the common marmoset (Hiroyama et al., 2006). Recently, abundant production of enucleated RBCs from human ES cells was reported (Lu et al., 2008).

Taken together, we can now produce mature RBCs by in vitro culture of ES cells or the hematopoietic stem/progenitor cells present in umbilical cord blood. In practice, however, the efficiency of RBC generation varies with the quality of the ES cell line or the umbilical cord blood sample. Since ES cell lines can be utilized repeatedly, derivation of RBCs from ES cells appears to be more practical. However, even with optimal experimental procedures and the most appropriate ES cell line the generation of abundant RBCs directly from primate ES cells is a costly and time-consuming process (Hiroyama et al., 2006; Lu et al., 2008). If human erythroid progenitor cell lines can be established that have efficient production of mature RBCs, they would provide a much more useful resource than ES cell lines.

\section{Establishment of mouse RBC progenitor cell lines}

Several mouse and human erythroid cell lines have been established. However, to the best of our knowledge, there is no cell line that can efficiently differentiate into enucleated RBCs. For example, the human erythroid cell line K562, derived from chronic myelogenous leukemia cells, can differentiate to mature erythroid cells and produce haemoglobin but cannot produce enucleated RBCs.

It is generally difficult to establish hematopoietic cell lines from adult hematopoietic stem or progenitor cells, since these somatic cells are quite sensitive to DNA damage and are unable to maintain the lengths of their telomere repeats on serial passage (Lansdorp, 2005). In contrast, ES cells are relatively resistant to DNA damage and maintain telomere length on serial passage (Lansdorp, 2005). Therefore, we speculated that these characteristics of ES cells might be advantageous for the establishment of cell lines, since differentiated cells derived from ES cells should retain these beneficial characteristics. In addition, mouse cells tend to immortalize more readily than human cells. Hence, we attempted to evaluate the feasibility of establishing hematopoietic cell lines, erythroid cell lines in particular, from mouse ES cells. 


\subsection{Establishment of RBC progenitor cell lines from mouse ES cells}

To induce differentiation of hematopoietic cells from mouse ES cells, we cultured ES cells using OP9 feeder cells (Nakano et al., 1994; Nakano et al., 1996; Kodama et al., 1994) in the presence of specific factors (Hiroyama et al., 2008). OP9 cells were used not only for induction of hematopoietic differentiation but also for establishment of cell lines in the early phase of long term culture of the induced hematopoietic cells (Hiroyama et al., 2008). In most cases, the induced cells stopped proliferating within two months of the initial induction of differentiation from ES cells (Hiroyama et al., 2008). This phenomenon is similar to that observed in primary culture of human cells such as fibroblasts, the so-called "crisis" of primary cells. In general, normal human cells cannot bypass this crisis stage and thus it is impossible to obtain immortalized cells from normal cells by continuous culture alone.

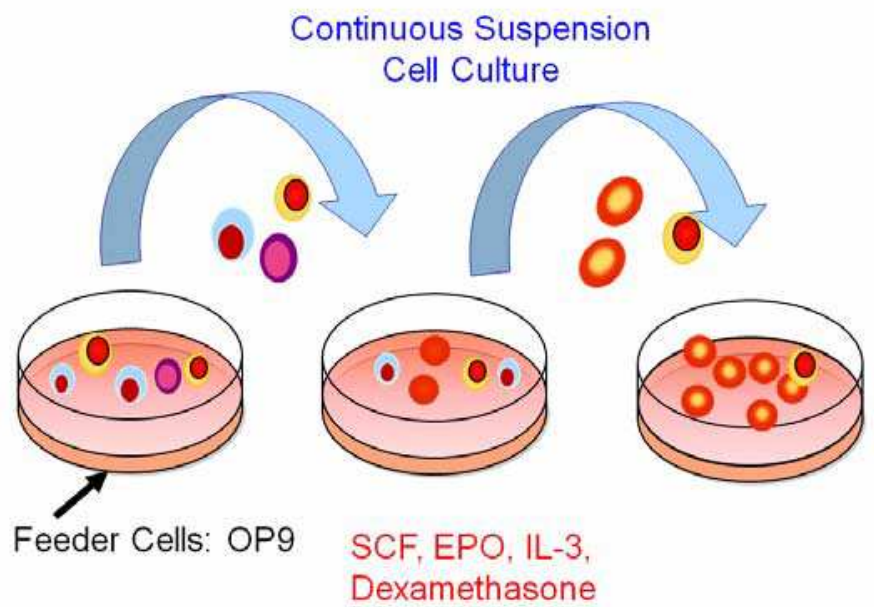

Fig. 3. A diagrammatic outline of the method to establish erythroid cell lines from ES cells.

Induced cells that could proliferate continuously for approximately two months (60 days) were cultured in the absence of OP9 cells and in the presence of hematopoietic humoral factors (Figure 3). Cells that continued to proliferate in the absence of OP9 cells were selected to establish cell lines. These cell lines acquired independency from OP9 cells within three months of the initial induction of differentiation from ES cells (Hiroyama et al., 2008). At approximately four months after initial induction, we sought to determine the factor(s) that were essential for the proliferation of each cell line. After this evaluation, each cell line was cultured in the presence of these essential factor(s) alone with changes of the medium every two or three days.

In addition to the method described in Figure 3 (Method A), we developed a second protocol (Method B) identical to Method A but omitting IL-3 at all stages. We attempted long term cultures of 63 lines, 51 with Method A and 12 with Method B. Five independent immortalized cell lines were successfully established, 4 with Method A and 1 with Method B (Hiroyama et al., 2008). These five cell lines continued to proliferate for more than a year. Morphological and flow cytometric analyses suggested that three of the lines were erythroid in nature, while the other two were mast cell-like (Hiroyama et al., 2008). We designated the erythroid cell lines MEDEP ( mouse ES cell-derived erythroid progenitor line) and the mast 
cell-like cell lines MEDMC ( $\underline{\text { mouse }} \underline{\mathrm{E} S}$ cell-derived mast cell line). MEDEP-E14, MEDEPBRC4, and MEDEP-BRC5 were derived from E14TG2a (129 strain), BRC4 (C57BL/6N strain), and BRC5 (C57BL/6N strain) mouse ES cell lines, respectively. The presence of IL-3 in the culture medium (Method A) may not be necessary for the establishment of erythroid cell lines, as we were able to establish one erythroid line, MEDEP-BRC4, following culture of the cells in the absence of IL-3 (Method B) (Hiroyama et al., 2008). MEDEP cells could proliferate from single cells following sorting by flow cytometry, i.e., cloning was possible.

All three MEDEP cell lines retained the morphological characteristics of erythroid cells and also showed cytokine dependency after cloning (Hiroyama et al., 2008). MEDEP-E14 and MEDEP-BRC5 were dependent on erythropoietin (EPO) and stem cell factor (SCF), respectively (Hiroyama et al., 2008). Although MEDEP-BRC5 appeared to respond to EPO, it could not proliferate long term in the presence of EPO alone. MEDEP-BRC4 proliferated most efficiently in the presence of SCF, EPO and dexamethasone (Hiroyama et al., 2008). The cytokine dependency of these MEDEP cell lines has not changed since they were induced to differentiate from ES cells more than a year ago.

RT-PCR analyses demonstrated that all MEDEP lines expressed genes specific for erythroid cells: GATA-1, EKLF (Erythroid Krüppel-like factor) and EPOR (erythropoietin receptor) (Hiroyama et al., 2008). In addition, all MEDEP lines expressed $\alpha$ - and $\beta$-globin, but not $\gamma-$, $\varepsilon-$, or $\zeta$-globin (Hiroyama et al., 2008), indicating that they were adult and not primitive erythroid progenitor cells. Since it has been reported that definitive erythropoiesis can be induced in mouse ES cells, i.e., the induction of adult type erythroid cells (Nakano et al., 1996), all MEDEP lines appear to be derived from adult type erythroid progenitor cells.

\subsection{In vitro differentiation of MEDEP}

Next, we evaluated the potential of MEDEP cells to differentiate into more mature erythroid cells and found that the various lines could be induced to differentiate by the following treatments: MEDEP-E14 by deprivation of EPO; MEDEP-BRC5 by deprivation of SCF and addition of EPO; and, MEDEP-BRC4 by deprivation of SCF and dexamethasone and addition of EPO (Hiroyama et al., 2008). EPO appeared to be necessary for MEDEP-BRC5 and MEDEP-BRC4 cells to maintain cell viability during the differentiation process.

The three MEDEP lines exhibited differential expression of TER119 (a cell surface antigen specific for mature erythroid cells) and CD71 (transferrin receptor). For example, expression of CD71 was slightly higher in MEDEP-E14 cells than in MEDEP-BRC5 cells (Hiroyama et al., 2008). TER119-CD71- cells differentiate first to TER119-CD71+ cells, subsequently to TER119 ${ }^{++}$CD71 ${ }^{+}$cells, and then finally to TER119+CD71- cells (Miharada et al., 2005). Consistent with the differences in their cytokine dependency, the three MEDEP cell lines appeared to represent different stages of erythroid differentiation. Nevertheless, after induction of differentiation in vitro by the methods described above, expression of TER119 and CD71 in each of the MEDEP lines exhibited a pattern consistent with a more mature lineage (Hiroyama et al., 2008). This expression pattern suggests that each of the three lines was able to differentiate into a more mature lineage. At present, the cause of the variability between MEDEP cell lines remains uncertain. However, these results clearly demonstrated that erythroid progenitor cells could be immortalized at different stages of their differentiation.

Of note, the vast majority of cells in each MEDEP line could differentiate into more mature cells, although each MEDEP line included cells possessing abnormal karyotypes (Hiroyama et al., 2008). This result strongly suggested that cells with abnormal karyotypes still retained 
the potential to differentiate into more mature erythroid cells. In general, most immortalized cell lines are not necessarily homogenous in many aspects such as karyotype, genotype, phenotype etc., even after cloning. The emergence of cells possessing different characteristics is often observed following long term utilization of immortalized cell lines. Hence, periodic recloning and selection of cell lines is recommended to maintain cell cultures with desirable characteristics for clinical application.

MEDEP-E14

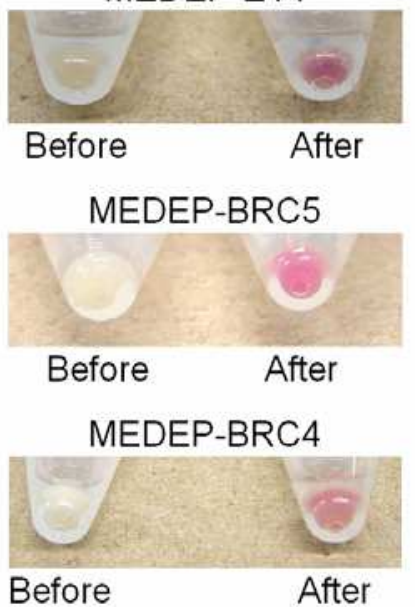

Fig. 4. MEDEP cell pellets show different coloration before and after differentiation.

Following induction of differentiation of MEDEP cells in vitro, the cell pellets collected after centrifugation appeared red while those before differentiation were white (Figure 4). In addition, following differentiation, enucleated cells could be identified by flow cytometric analysis using SYTO85 staining (Hiroyama et al., 2008). Morphological analysis confirmed that enucleated RBCs were present in addition to very mature erythroblasts (Figure 5).

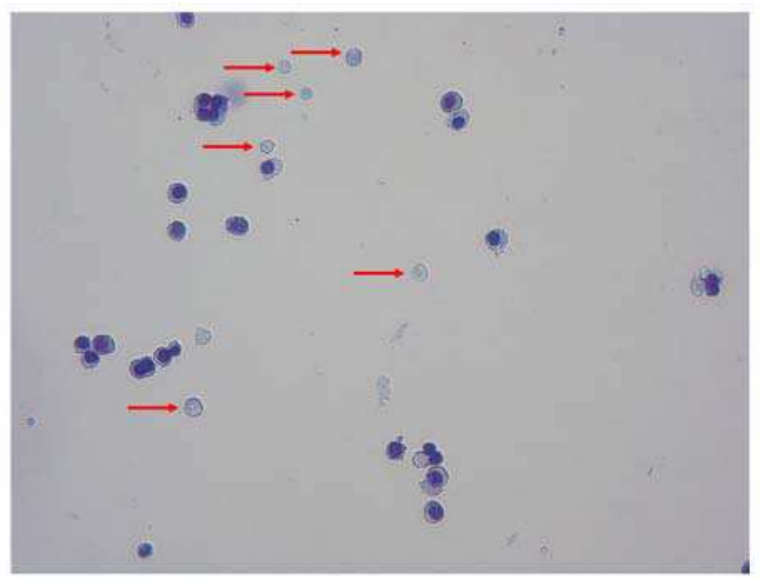

Fig. 5. Enucleated RBCs produced from MEDEP cells. Arrows indicate enucleated cells. 


\subsection{In vivo proliferation and differentiation of MEDEP}

To evaluate the functional potential of MEDEP cells in vivo, we established a subline of MEDEP-E14 expressing the GFP marker Venus (Nagai et al., 2002). Although the expression of TER119 was slightly higher in MEDEP-E14-Venus cells than in parent MEDEP-E14 cells, the MEDEP-E14-Venus cells retained the ability to proliferate and differentiate into more mature erythroid cells in vitro (Hiroyama et al., 2008).

In general, the ablation of endogenous hematopoietic cells in mice is required to allow efficient detection of transplanted hematopoietic cells. Acute anemia induced by phlebotomy or hemolysis is commonly used in the study of urgent erythropoiesis (Alter et al., 1982; Miharada et al., 2005). We induced acute anemia in mice by intraperitoneal injection of phenylhydrazine, an inducer of hemolysis, and transplanted MEDEP-E14-Venus cells ( $2 \times 10^{7}$ cells/mouse) 24 hours later. Three days after transplantation, Venus-positive cells were present in the bone marrow and spleen (Hiroyama et al., 2008). Since the spleen is the major organ supporting urgent erythropoiesis in mice (Miharada et al., 2005), the transplanted cells were more abundant in the spleen than the bone marrow (Hiroyama et al., 2008). Venus-positive cells (the transplanted cells) demonstrated a phenotype consistent with differentiation into more mature erythroid cells compared to their phenotype just before transplantation (Hiroyama et al., 2008). Of note, MEDEP-E14-Venus cells differentiated into much more mature lineages in vivo than they did in vitro (Hiroyama et al., 2008).

To investigate whether transplanted cells could proliferate in vivo, we determined the absolute number and proportion (\%) of Venus-positive cells in the spleen in a cell transplantation experiment. The absolute number of Venus-positive cells was elevated approximately two fold at three days compared to one day after cell transplantation (Hiroyama et al., 2008). This result indicates that transplanted cells can proliferate in vivo.

The expression of Venus in the transplanted cells decreased following their differentiation, i.e., the expression of Venus was lower in TER119 ${ }^{++}$cells than in TER119+ cells (Hiroyama et al., 2008). Thus, although we could not detect Venus-positive cells in peripheral blood, this was likely the result of disappearance of Venus following terminal differentiation. We therefore sought to confirm that MEDEP cells could differentiate into terminallydifferentiated RBCs in vivo.

\subsection{Increase of RBC number in mice suffering from acute anemia following transplantation of MEDEP}

MEDEP cells $\left(2 \times 10^{7}\right.$ cells/mouse) were transplanted 24 hours after induction of acute anemia. As a control experiment, MEDMC cells ( $2 \times 10^{7}$ cells/mouse) were transplanted into control mice. Since $2 \times 10^{7}$ transplanted RBCs correspond to a mere $2 \mu \mathrm{l}$ of transfused cells, the number of RBCs in the transplanted mice will only increase if these transplanted MEDEP cells proliferate to some degree and differentiate into terminally-differentiated RBCs in vivo. Five days after transplantation, blood cell counts were performed in peripheral blood. The transplantation of MEDEP-E14 significantly ameliorated anemia compared to the control (Figure 6). The data obtained from the mice transplanted with control cells did not differ significantly from the data obtained from anemic mice that were not transplanted with any cells.

Since the RBC count in peripheral blood reflects the number of enucleated cells, whereas erythroblasts (nucleated cells) are included in the count of white blood cells (WBC), the 
$\mathrm{RBC}$

$\left(\times 10^{4} / \mathrm{ml}\right)$

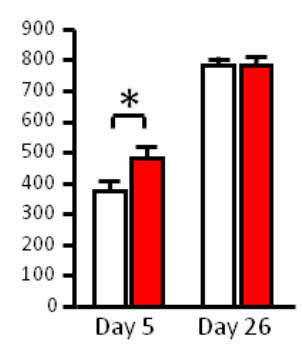

Hemoglobin

$(\mathrm{g} / \mathrm{dl})$
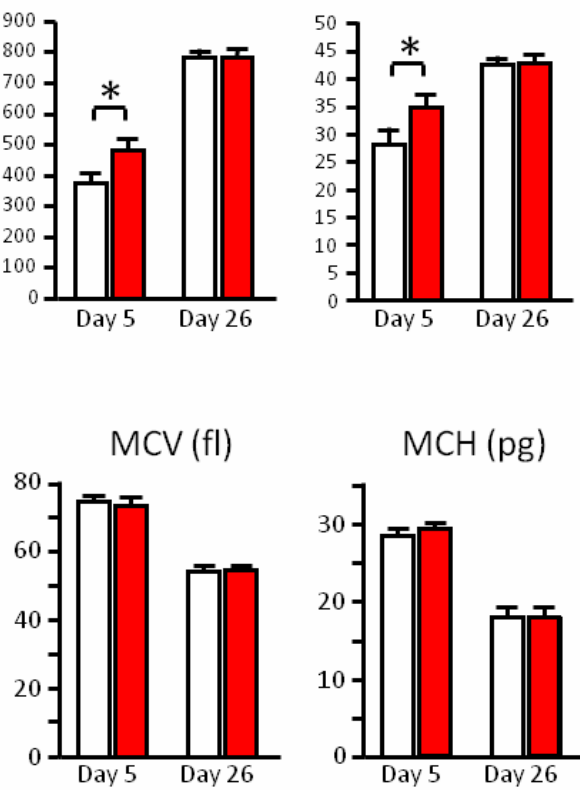

$\mathrm{MCH}(\mathrm{pg})$

$\mathrm{MCV}(\mathrm{fl})$

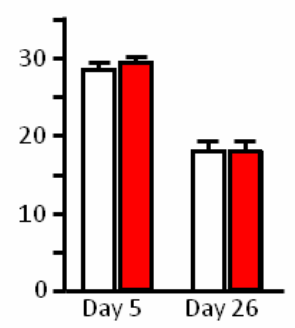

Hematocrit

(\%)

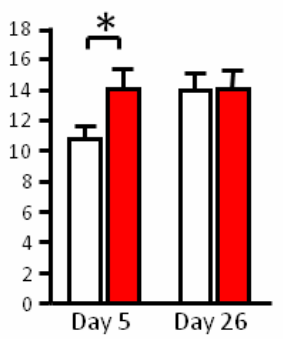

$\mathrm{MCHC}(\mathrm{g} / \mathrm{dl})$

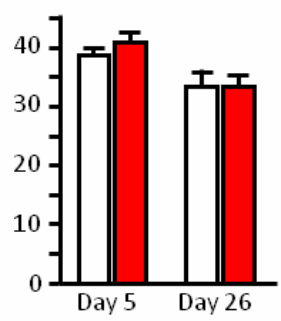

Fig. 6. Blood counts in control and MEDEP transplanted mice. White bars and red bars indicate mice transplanted with control cells and MEDEP cells, respectively. Asterisks indicate statistically significant differences $(\mathrm{P}<0.05)$.

increased number of RBC observed in mice transplanted with MEDEP cells indicated that the transplanted MEDEP cells could efficiently differentiate into enucleated cells (Hiroyama et al., 2008). The life span of RBCs is approximately 50 days in the mouse; therefore, it is highly likely that the RBCs produced from the transplanted MEDEP cells accumulated in the transplanted mouse.

Increases in mean corpuscular volume (MCV), mean corpuscular hemoglobin $(\mathrm{MCH})$, and $\mathrm{MCH}$ concentration (MCHC) (Figure 6) are commonly observed in the recovery phase of acute anemia (Miharada et al., 2005). In addition, an increase in the number of WBC is observed in the recovery phase of acute anemia (Hiroyama et al., 2008) and is due to the presence of erythroblasts in the peripheral blood, since erythroblasts are counted as WBC by the automatic counter (Miharada et al., 2005). Given that there was no difference in MCV, $\mathrm{MCH}$ and $\mathrm{MCHC}$ levels between the transplanted and control mice in the recovery phase of acute anemia (Figure 6), RBCs derived from MEDEP cells in vivo appeared to possess characteristics similar to those derived from erythroid progenitor cells in the host mice. Twenty-six days after transplantation (27 days after the induction of acute anemia), all mice had recovered from the anemia and there were no differences in the blood counts of the two groups (Figure 6).

The transplantation of MEDEP-E14-Venus and MEDEP-BRC5 cells also ameliorated anemia compared to the control (Hiroyama et al., 2008). However, the transplantation of MEDEP- 
BRC5 cells appeared to be less effective for amelioration of anemia than MEDEP-E14 cells (Hiroyama et al., 2008). Given that the in vitro proliferation activity of MEDEP-BRC5 cells was lower than that of MEDEP-E14 cells, the in vivo proliferation activity of MEDEP-BRC5 cells might have also been lower than that of MEDEP-E14 cells (Hiroyama et al., 2008). In addition, hemoglobin synthesis in MEDEP-BRC5 might have been less efficient than in MEDEP-E14 (Hiroyama et al., 2008).

Immunogenicity of human ES cell derivatives is one of the potential obstacles to their clinical use (Drukker and Benvenisty, 2004; Boyd et al., 2005). Indeed, transplanted MEDEP cells do not ameliorate acute anemia in mouse strains other than those from which the individual lines were derived or in immuno-deficient mice, suggesting immunological rejection by the heterologous strains. Hence, if human erythroid cell lines are to be established, the clinical application of these cells might involve application of a number of lines that express different major histo-compatibility (MHC) antigens.

\subsection{Lack of tumorigenicity of MEDEP}

Approximately three months after transplantation, Venus-positive cells were absent from the bone marrow and spleen of mice transplanted with MEDEP-E14-Venus cells (Hiroyama et al., 2008). In addition, although we examined all other transplanted mice up to 6 months after transplantation, no tumors were observed in MEDEP-transplanted mice or MEDMCtransplanted control mice (Hiroyama et al., 2008). Furthermore, subcutaneous transplantation of MEDEP cells ( $2 \times 10^{7}$ cells/injection site) did not give rise to any tumors, whereas subcutaneous transplantation of the same number of parent ES cells led to the formation of a teratoma (Hiroyama et al., 2008).

What mechanism underlies the lack of tumorigenicity of MEDEP? MEDEP cells can only be successfully cultured in the presence of excess growth factor(s) and cannot proliferate or survive without such growth factor(s). Therefore, MEDEP cells cannot proliferate or survive in vivo in the presence of the normal range of growth factors. Indeed, when MEDEP-E14Venus cells were transplanted into mice that were not in an anemic condition, an increase in RBC numbers in the peripheral blood was not observed and Venus-positive cells were not detected in the bone marrow or spleen by flow cytometry a few days after transplantation. By contrast, when MEDEP cells were transplanted into mice suffering from acute anemia, the concentration of growth factors was upregulated in the mice due to anemia and thus MEDEP cells proliferated. Following recovery from anemia, there was a reduction in growth factors in the serum and MEDEP cells no longer proliferated or survived. We suggest that the concentration of growth factors determines whether or not MEDEP cells can proliferate with the potential for tumorigenicity.

Therefore, establishment of growth factor-dependent erythroid cell lines may be of particular value for clinical applications. Nevertheless, when human erythroid cell lines are established, the tumorigenic potential of these lines will still need to be exhaustively analyzed prior to their use in the clinic (Vogel, 2005; Hentze et al., 2007). It may also be advisable to engineer such cells so that they can be eliminated should a malignant phenotype arise for any reason (Schuldiner et al., 2003).

\subsection{RBCs derived from MEDEP are functional in vivo}

To confirm that the RBCs derived from the transplanted MEDEP cells are functional in vivo, we monitored the response of transplanted mice to a second induction of hemolysis. 
Hemolysis was induced and followed by cell transplantation; a second induction of hemolysis was performed five days after cell transplantation (Figure 7) (Hiroyama et al., 2008). Analysis of blood counts was not performed at any time point in this experiment, because collection of peripheral blood would affect the results. We observed that one of the eight mice in the group transplanted with MEDEP-E14 cells died, while seven of the eight mice in the group transplanted with control cells (MEDMC-NT2) died (Figure 7). Mice that did not receive any transplanted cells showed a mortality rate similar to that of mice transplanted with control cells. This result is consistent with observed increase in RBC numbers five days after cell transplantation (Figure 6). In other words, this result indicated that RBCs derived from MEDEP cells were functional in vivo and that mice transplanted with MEDEP cells could survive a severe acute anemia caused by a second induction of hemolysis.

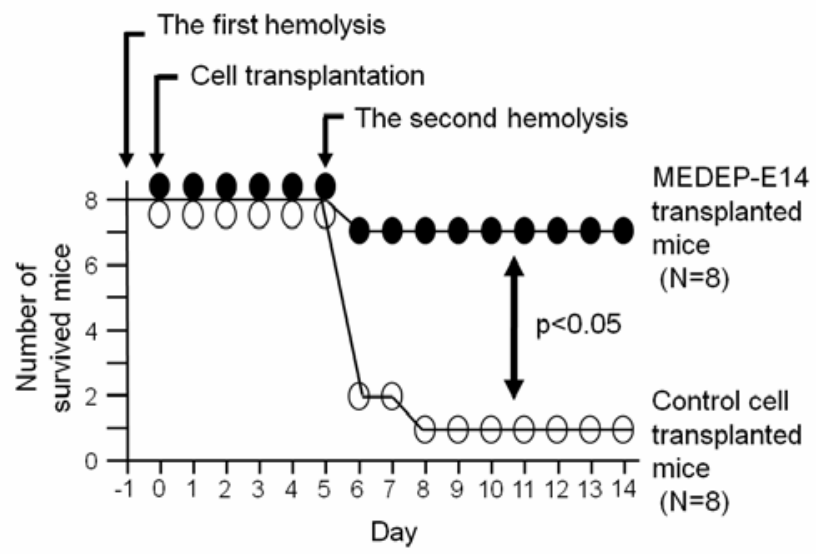

Fig. 7. Survival curves of mice transplanted with MEDEP or control cells following severe acute anemia.

\section{Strategy for clinical use of hematopoietic cells produced in vitro}

The most critical obstacle to use of ES cell-derived cells is the potential for tumorigenicity. First, there is a risk that the transplanted cells include ES cells and that such contaminant cells could be tumorigenic. Second, even if ES cells can be completely excluded from the transplanted sample by some method, the transplanted cells may revert to an ES-like state and could be tumorigenic. Therefore, when we consider the possibility of clinical application of ES cell-derived cells, thorough preclinical studies need to be carried out.

Establishment of erythroid progenitor cell lines from human ES cells would provide a valuable source of material for further utilization. However, the risk of tumorigenicity of such cells is similar to that of ES cells since they are immortalized. As mentioned above, growth factor dependent cell lines that can proliferate only in the presence of excess growth factor(s) in vitro might offer candidate cell lines for use in the clinic. Those cells could be transplanted with a simultaneous injection of the requisite growth factors and, after achievement of their clinical purpose, the cells would be eliminated due to eventual deprivation of growth factor(s). In any case, the risk of tumorigenicity must be taken into account in the transplantation of nucleated cells derived from immortalized cells, since we cannot predict at present how these cells will behave after transplantation. 


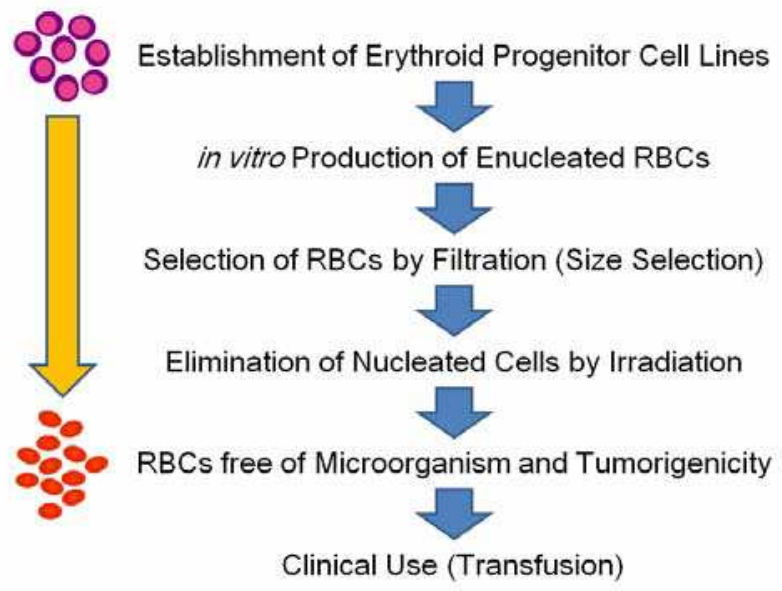

Fig. 8. Strategy for production of transfusable RBCs from immortalized erythroid cell lines.

On the other hand, RBCs and platelets are very specific cells in the body that lack nuclei following terminal differentiation. These anuclear cells cannot form tumors in vivo. Therefore, RBCs and platelets, even if they are derived from immortalized cells, could be transfused without concerns about possible tumorigenicity. Following production of RBCs or platelets in vitro, pure populations can be selected by size using filtration, since they are much smaller than normal nucleated cells. In addition, any nucleated cells, which are still present in the sample after size selection, could be eliminated by irradiation. Irradiation of RBC samples is already routinely performed to eliminate lymphocytes in some clinical protocols. Therefore, if we can establish an in vitro culture system that enables abundant production of RBCs or platelets, then the cells could be applied in the clinic using the procedures described above (Figure 8 ). To establish such a culture system, progenitor cell lines able to produce enucleated cells in vitro will be essential.

\section{Establishment of RBC progenitor cell lines from human ES cells or human iPS cells}

The reproducible establishment of MEDEP cell lines described above strongly suggests that similar erythroid cell lines could also be established from human ES cells. We, therefore, sought to establish human erythroid progenitor cell lines. The methods used to induce hematopoietic cells from ES cells and to culture the induced hematopoietic cells are similar to those established for MEDEP cell lines (Figure 3), with the exception that the corresponding human factors were applied and IL-3 was not used at all. Exclusion of IL-3 was based on our finding that the compound was not necessary for establishment of MEDEP cell lines (see above).

Initially, we used three human ES cell lines, KhES-1, KhES-2 and KhES-3, that had been established in Japan. However, we were unable to induce hematopoietic cells from all three lines and, compared to mouse ES cells, the efficiency of production of hematopoietic cells was extremely low. As a result, we have yet been successful in establishing immortalized cell lines from the three ES cell lines. 
During the course of the experiments using these human ES cell lines, a breakthrough discovery in the field of regenerative medicine was reported, namely, the establishment of human iPS cells (Takahashi et al., 2007) following that of mouse iPS cells (Takahashi and Yamanaka, 2006). This discovery prompted us to establish human iPS cells, since the characteristics of pluripotent stem cells, such as ES cells, differ among cell lines. In other words, we speculated that we could obtain iPS cell lines that could have the ability to differentiate into hematopoietic cells. We were able to establish a number of human iPS cell lines using fibroblast-like cells derived from neonatal tissues (Fujioka et al., in press). Fortunately, we were able to induce abundant numbers of hematopoietic cells from some of these iPS cell lines and also to establish immortalized hematopoietic cell lines from the induced hematopoietic cells. Currently, we are investigating the characteristics of these immortalized hematopoietic cell lines. Some seem to be erythroid cell lines.

\section{Concluding remarks}

We propose that by utilizing ES cells or iPS cells it will be possible to establish human erythroid progenitor cell lines able to produce enucleated RBCs. RBCs produced by in vitro culture of such erythroid cell lines could be applied in the clinic following size selection and elimination of nucleated cells by irradiation.

Once an erythroid cell line able to produce $\mathrm{O} / \mathrm{RhD}(-) \mathrm{RBC}$ s is established, it could be used as necessary to produce RBCs for transfusion into patients around the world. Obviously, there would be a few patients for whom this approach would not be practicable, such as those possessing Rh-null RBCs.

\section{References}

Alter, B.P., Campbell, A.S., Holland, J.G. \& Friend, C. (1982) Increased mouse minor hemoglobin during erythroid stress: a model for hemoglobin regulation. Experimental Hematology 10: 754-760.

Boyd, A.S., Higashi, Y. \& Wood, K.J. (2005) Transplanting stem cells: potential targets for immune attack. Modulating the immune response against embryonic stem cell transplantation. Advanced Drug Delivery Reviews 57: 1944-1969.

Carotta, S., Pilat, S., Mairhofer, A., Schmidt, U., Dolznig, H., Steinlein, P. \& Beug, H. (2004) Directed differentiation and mass cultivation of pure erythroid progenitors from mouse embryonic stem cells. Blood 104: 1873-1880.

Cerdan, C., Rouleau, A. \& Bhatia, M. (2004) VEGF-A165 augments erythropoietic development from human embryonic stem cells. Blood 103: 2504-2512.

Chadwick, K., Wang, L., Li, L., Menendez, P., Murdoch, B., Rouleau, A. \& Bhatia, M. (2003) Cytokines and BMP-4 promote hematopoietic differentiation of human embryonic stem cells. Blood 102: 906-915.

Douay, L. \& Andreu, G. (2007). Ex vivo production of human red blood cells from hematopoietic stem cells: what is the future in transfusion? Transfusion Medicine Reviews 21: 91-100.

Drukker, M. \& Benvenisty, N. (2004) The immunogenicity of human embryonic stemderived cells. Trends in Biotechnology 22: 136-141.

Fujioka, T., Shimizu, N., Yoshino, K., Miyoshi, H. \& Nakamura, Y. (2010) Establishment of induced pluripotent stem cells from human neonatal tissues. Human Cell (in press). 
Giarratana, M.C., Kobari, L., Lapillonne, H., Chalmers, D., Kiger, L., Cynober, T., Marden, M.C., Wajcman, H. \& Douay, L. (2005) Ex vivo generation of fully mature human red blood cells from hematopoietic stem cells. Natute Biotechnology 23: 69-74.

Hanspal, M., Smockova, Y. \& Uong, Q. (1998). Molecular identification and functional characterization of a novel protein that mediates the attachment of erythroblasts to macrophages. Blood 92 : 2940-2950.

Hentze, H., Graichen, R. \& Colman, A. (2007) Cell therapy and the safety of embryonic stem cell-derived grafts. Trends in Biotechnology 25 : 24-32.

Hiroyama, T., Miharada, K., Aoki, N., Fujioka, T., Sudo, K., Danjo, I., Nagasawa, T. \& Nakamura, Y. (2006) Long-lasting in vitro hematopoiesis derived from primate embryonic stem cells. Experimental Hematology 34: 760-769.

Hiroyama, T., Sudo, K., Aoki, N., Miharada, K., Danjo, I., Fujioka, T., Nagasawa, T. \& Nakamura, Y. (2008). Establishment of mouse embryonic stem cell-derived erythroid progenitor cell lines able to produce functional red blood cells. PLoS ONE 3, e1544.

Iavarone, A., King, E.R., Dai, X.M., Leone, G., Stanley, E.R. \& Lasorella, A. (2004). Retinoblastoma promotes definitive erythropoiesis by repressing Id 2 in fetal liver macrophages. Nature 432 : 1040-1045.

Kaufman, D.S., Hanson, E.T., Lewis, R.L., Auerbach, R. \& Thomson, J.A. (2001) Hematopoietic colony-forming cells derived from human embryonic stem cells. Proceedings of the National Academy of Sciences U.S.A. 98 : 10716-10721

Keller, G., Kennedy, M., Papayannopoulou, T. \& Wiles, M.V. (1993) Hematopoietic commitment during embryonic stem cell differentiation in culture. Molecular and Cellular Biology 13: 473-486.

Kingsley, P.D., Malik, J., Fantauzzo, K.A. \& Palis, J. (2004). Yolk sac-derived primitive erythroblasts enucleate during mammalian embryogenesis. Blood 104 : 19-25.

Kodama, H., Nose, M., Niida, S., Nishikawa, S. \& Nishikawa, S. (1994) Involvement of the ckit receptor in the adhesion of hematopoietic stem cells to stromal cells. Experimental Hematology 22: 979-984.

Kurita, R., Sasaki, E., Yokoo, T., Hiroyama, T., Takasugi, K., Imoto, H., Izawa, K., Dong, Y., Hashiguchi, T., Soda, Y., Maeda, T., Suehiro, Y., Tanioka, Y., Nakazaki, Y. \& Tani, K. (2006) Tal1/Scl gene transduction using a lentiviral vector stimulates highly efficient hematopoietic cell differentiation from common marmoset (Callithrix jacchus) embryonic stem cells. Stem Cells 24: 2014-2022.

Lansdorp, P.M. (2005) Role of telomerase in hematopoietic stem cells. Annals of the New York Academy of Sciences 1044: 220-227.

Lee, J.C., Gimm, J.A., Lo, A.J., Koury, M.J., Krauss, S.W., Mohandas, N. \& Chasis, J.A. (2004). Mechanism of protein sorting during erythroblast enucleation: role of cytoskeletal connectivity. Blood 103 : 1912-1919.

Li, F., Lu, S., Vida, L., Thomson, J.A. \& Honig, G.R. (2001) Bone morphogenetic protein 4 induces efficient hematopoietic differentiation of rhesus monkey embryonic stem cells in vitro. Blood 98: 335-342.

Looney, M.R., Gilliss, B.M. \& Matthay, M.A. (2010) Pathophysiology of transfusion-related acute lung injury. Current Opinion in Hematology 17: 418-423. 
Lu, S.J., Feng, Q., Park, J.S., Vida, L., Lee, B.S., Strausbauch, M., Wettstein, P.J., Honig, G.R. \& Lanza, R. (2008) Biologic properties and enucleation of red blood cells from human embryonic stem cells. Blood 112: 4475-4484.

Miharada, K., Hiroyama, T., Sudo, K., Nagasawa, T. \& Nakamura, Y. (2005) Lipocalin 2 functions as a negative regulator of red blood cell production in an autocrine fashion. FASEB Journal 19: 1881-1883.

Miharada, K., Hiroyama, T., Sudo, K., Nagasawa, T. \& Nakamura, Y. (2006) Efficient enucleation of erythroblasts differentiated in vitro from hematopoietic stem and progenitor cells. Nature Biotechnology 24: 1255-1256.

Nagai, T., Ibata, K., Park, E.S., Kubota, M., Mikoshiba, K. \& Miyawaki, A. (2002) A variant of yellow fluorescent protein with fast and efficient maturation for cell-biological applications. Nature Biotechnology 20: 87-90.

Nakano, T., Kodama, H. \& Honjo, T. (1994) Generation of lymphohematopoietic cells from embryonic stem cells in culture. Science 265: 1098-1101.

Nakano, T., Kodama, H. \& Honjo, T. (1996) In vitro development of primitive and definitive erythrocytes from different precursors. Science 272: 722-724.

Neildez-Nguyen, T.M., Wajcman, H., Marden, M.C., Bensidhoum, M., Moncollin, V., Giarratana, M.C., Kobari, L., Thierry, D. \& Douay, L. (2002) Human erythroid cells produced ex vivo at large scale differentiate into red blood cells in vivo. Nature Biotechnology 20: 467-472.

Ohneda, O. \& Bautch, V.L. (1997). Murine endothelial cells support fetal liver erythropoiesis and myelopoiesis via distinct interactions. British Journal of Haematology 98, 798-808.

Olivier, E.N., Qiu, C., Velho, M., Hirsch, R.E. \& Bouhassira, E.E. (2006) Large-scale production of embryonic red blood cells from human embryonic stem cells. Experimental Hematology 34: 1635-1642.

Schuldiner, M., Itskovitz-Eldor, J. \& Benvenisty, N. (2003) Selective ablation of human embryonic stem cells expressing a "suicide" gene. Stem cells 21: 257-265.

Silliman, C.C., Fung, Y.L., Ball, J.B. \& Khan, S.Y. (2009) Transfusion-related acute lung injury (TRALI): current concepts and misconceptions. Blood Reviews 23: 245-255.

Spike, B.T., Dirlam, A., Dibling, B.C., Marvin, J., Williams, B.O., Jacks, T. \& Macleod, K.F. (2004). The $\mathrm{Rb}$ tumor suppressor is required for stress erythropoiesis. EMBO Journal 23: 4319-4329.

Takahashi, K. \& Yamanaka, S. (2006) Induction of pluripotent stem cells from mouse embryonic and adult fibroblast cultures by defined factors. Cell 126: 663-676.

Takahashi, K., Tanabe, K., Ohnuki, M., Narita, M., Ichisaka, T., Tomoda, K. \& Yamanaka, S. (2007) Induction of pluripotent stem cells from adult human fibroblasts by defined factors. Cell 131: 861-872.

Umeda, K., Heike, T., Yoshimoto, M., Shiota, M., Suemori, H., Luo, H.Y., Chui, D.H., Torii, R., Shibuya, M., Nakatsuji, N. \& Nakahata, T. (2004) Development of primitive and definitive hematopoiesis from nonhuman primate embryonic stem cells in vitro. Development 131: 1869-1879.

Vodyanik, M.A., Bork, J.A., Thomson, J.A. \& Slukvin, I.I. (2005) Human embryonic stem cell-derived CD34+ cells: efficient production in the coculture with OP9 stromal cells and analysis of lymphohematopoietic potential. Blood 105: 617-626. 
Vogel, G. (2005) Ready or not? Human ES cells head toward the clinic. Science 308: 15341538.

Wang, L., Li, L., Menendez, P., Cerdan, C. \& Bhatia, M. (2005). Human embryonic stem cells maintained in the absence of mouse embryonic fibroblasts or conditioned media are capable of hematopoietic development. Blood 105: 4598-4603.

Wang, L., Menendez, P., Cerdan, C. \& Bhatia, M. (2005). Hematopoietic development from human embryonic stem cell lines. Experimental Hematology 33: 987-996.

Wang, L., Menendez, P., Shojaei, F., Li, L., Mazurier, F., Dick, J.E., Cerdan, C., Levac, K. \& Bhatia, M. (2005) Generation of hematopoietic repopulating cells from human embryonic stem cells independent of ectopic HOXB4 expression. Jouranl of Experimental Medicine 201: 1603-1614.

Yanai, N., Sato, Y. \& Obinata, M. (1997). A new type-II membrane protein in erythropoietic organs enhances erythropoiesis. Leukemia (Supplement 3) 11: 484-485.

Yoshida, H., Kawane, K., Koike, M., Mori, Y., Uchiyama, Y. \& Nagata, S. (2005). Phosphatidylserine-dependent engulfment by macrophages of nuclei from erythroid precursor cells. Nature 437: 754-758. 


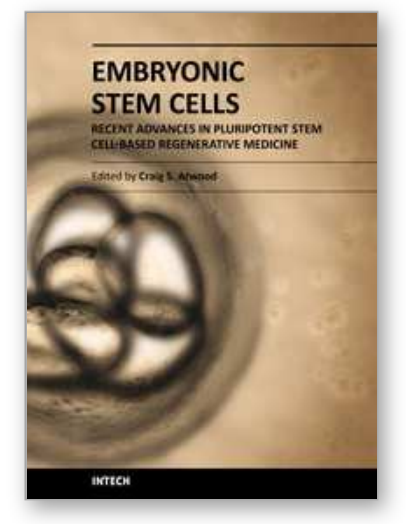

\section{Embryonic Stem Cells - Recent Advances in Pluripotent Stem Cell- Based Regenerative Medicine}

Edited by Prof. Craig Atwood

ISBN 978-953-307-198-5

Hard cover, 410 pages

Publisher InTech

Published online 26, April, 2011

Published in print edition April, 2011

Pluripotent stem cells have the potential to revolutionise medicine, providing treatment options for a wide range of diseases and conditions that currently lack therapies or cures. This book describes recent advances in the generation of tissue specific cell types for regenerative applications, as well as the obstacles that need to be overcome in order to recognize the potential of these cells.

\section{How to reference}

In order to correctly reference this scholarly work, feel free to copy and paste the following:

Yukio Nakamura (2011). ES Cell-derived Erythroid Cell Lines Able to Produce Mature Red Blood Cells, Embryonic Stem Cells - Recent Advances in Pluripotent Stem Cell-Based Regenerative Medicine, Prof. Craig Atwood (Ed.), ISBN: 978-953-307-198-5, InTech, Available from: http://www.intechopen.com/books/embryonicstem-cells-recent-advances-in-pluripotent-stem-cell-based-regenerative-medicine/es-cell-derived-erythroidcell-lines-able-to-produce-mature-red-blood-cells

\section{INTECH}

open science | open minds

\author{
InTech Europe \\ University Campus STeP Ri \\ Slavka Krautzeka 83/A \\ 51000 Rijeka, Croatia \\ Phone: +385 (51) 770447 \\ Fax: +385 (51) 686166 \\ www.intechopen.com
}

\author{
InTech China \\ Unit 405, Office Block, Hotel Equatorial Shanghai \\ No.65, Yan An Road (West), Shanghai, 200040, China \\ 中国上海市延安西路65号上海国际贵都大饭店办公楼 405 单元 \\ Phone: +86-21-62489820 \\ Fax: $+86-21-62489821$
}


(C) 2011 The Author(s). Licensee IntechOpen. This chapter is distributed under the terms of the Creative Commons Attribution-NonCommercialShareAlike-3.0 License, which permits use, distribution and reproduction for non-commercial purposes, provided the original is properly cited and derivative works building on this content are distributed under the same license. 